\title{
A Method to Induce Stem Cankers by Inoculating Nonwounded Populus Clones with Septoria musiva Spore Suspensions
}

Jared M. LeBoldus and Peter V. Blenis, Department of Renewable Resources, University of Alberta, Edmonton, AB T6G 2H1, Canada; and Barb R. Thomas, Alberta-Pacific Forest Industries Inc., Boyle, AB T0A 0M0, Canada

\begin{abstract}
LeBoldus, J. M., Blenis, P. V., and Thomas, B. R. 2010. A method to induce stem cankers by inoculating nonwounded Populus clones with Septoria musiva spore suspensions. Plant Dis. 94:1238-1242.

Most artificial inoculations of Populus spp. stems with Septoria musiva have required host wounding to induce canker development; in the absence of wounds, frequencies of cankers have been low. Three greenhouse inoculation experiments were conducted to demonstrate the reliability and repeatability of an inoculation method that did not require wounding. In the first, 16 clones of hybrid poplar were inoculated with three isolates of $S$. musiva to compare responses following wounding and inoculation with mycelium (wound inoculation) with responses following inoculation of nonwounded trees by spraying with a conidial suspension (spray inoculation). Stem disease severity among clones following spray inoculation was correlated with stem disease severity following wound inoculation. A significant clone-isolate interaction was detected with spray inoculation but not wound inoculation. In the other two greenhouse experiments, 29 clones of hybrid poplar and 69 clones of Populus balsamifera were inoculated with a spore suspension mixture of three isolates. In both cases, the experimental error was similar to that obtained in previous experiments, in which trees were wound inoculated, and was adequately small to permit detection of differences in responses among clones. Ultimately, field studies will be needed to determine the best inoculation method for predicting stem responses to this pathogen under field conditions. However, relative to wound inoculation, spray inoculation of nonwounded trees has the advantage of yielding faster results, permitting inoculation with a mixture of isolates, and not circumventing potential mechanisms for resisting penetration. The ability to infect stems without wounding creates opportunities for numerous types of epidemiological and disease control studies that are difficult to conduct with wound inoculation.
\end{abstract}

The expansion of short-rotation, highyield plantations of Populus spp. in Canada (11), the United States (11), and South America (1) has drawn attention to several important pathogens of this genus. In particular, the fungal pathogen Septoria musiva Peck (teleomorph = Mycosphaerella populorum G.E. Thomps.), the cause of leaf spots and stem cankers $(2-4,15)$, has become important in North America. Although severe leaf spot disease may cause premature defoliation (12), a single stem infection can girdle an infected tree or weaken it sufficiently to increase the risk of wind breakage (12). Outbreaks of this disease have resulted in severe damage and even plantation failure $(2,12,15)$. The potential losses and the difficulty in managing this disease by either chemical (12) or cultural control (12) has driven the need to develop a better understanding of the Populus spp.-S. musiva interaction in hopes of reducing losses.

Corresponding author: J. M. LeBoldus

E-mail: jaredl@ualberta.ca

Accepted for publication 21 June 2010.

doi:10.1094/PDIS-02-10-0094

(C) 2010 The American Phytopathological Society
To date, stem responses to $S$. musiva infection have been studied by initially wounding the stem and then applying the pathogen to the wound. To our knowledge, when inoculations have been attempted in the absence of wounding, the incidence of infection has been extremely low $(2,3,9,17)$. If it were possible to reliably obtain stem infections following application of spores to nonwounded trees, this would have two important benefits to Septoria research. First, in resistance trials, potential resistance mechanisms to penetration would not be circumvented, as may happen with wound inoculations. Second, opportunities would expand to conduct studies that are difficult to accomplish with wound inoculations (e.g., examining penetration and infection processes, evaluating the effect of temperature and duration of free water on infection, determining the relationship between inoculum concentration and disease severity, and comparing fungicide treatments). This article reports the results of three experiments that demonstrated that, in contrast to earlier reports, it is possible to obtain high levels of stem infection by spray inoculation of spores without stem wounding.

\section{MATERIALS AND METHODS}

Part I. Inoculation method comparison.

Poplar culture. Dormant branch cuttings from 16 clones of three hybrid poplar parentages (Table 1) were collected in March 2009 from the previous year's growth in research trials at the AlbertaPacific Forest Industries Inc. (Al-Pac) mill site in northern Alberta (approximate location $54^{\circ} \mathrm{N}, 112^{\circ} \mathrm{W}$ ). The branches were cut into $10-\mathrm{cm}$ sections, soaked in deionized water for $48 \mathrm{~h}$ at $4^{\circ} \mathrm{C}$, and planted into 12 cm-deep rootrainers (Spencer-Lemaire Rootrainers; Spencer-Lemaire Industries, Edmonton, AB, Canada) with only the topmost bud exposed above Metromix 290 growing media (Terra-Lite 2000 series; WR Grace and Company, Ajax, ON, Canada).

The cuttings were then placed into a greenhouse maintained at 20 and $15^{\circ} \mathrm{C}$ (day and night, respectively) with an 18-h photoperiod supplemented with artificial lights. The irradiance varied with cloud cover but was, on average, approximately $450 \mu \mathrm{mol}$ photons $\mathrm{m}^{-2} \mathrm{~s}^{-1}$ photosynthetically active radiation (PAR) at the rootrainer level. During the first 59 days, plants were fertilized biweekly with a 500 ppm solution of 15-30-15 fertilizer (Plant Products Company Ltd., Brampton, ON, Canada). At the end of the initial 60-day growth period, trees were transplanted from the rootrainers into $15-\mathrm{cm}$-diameter by $18-\mathrm{cm}$-deep plastic pots (Listo Products Ltd., Vancouver, BC, Canada) containing Metromix 290 growing medium amended with Nutricote 100-day slow-release 1313-13 fertilizer $\left(6.5 \% \mathrm{NO}_{3}-\mathrm{N}, 6.5 \% \mathrm{NH}_{4}{ }^{-}\right.$ $\mathrm{N}, 13 \% \mathrm{P}_{2} \mathrm{O}_{5}, 13 \% \mathrm{~K}_{2} \mathrm{O}, 1.2 \% \mathrm{Mg}, 0.02 \%$ $\mathrm{B}, 0.05 \% \mathrm{Cu}, 0.2 \%$ chelated $\mathrm{Fe}, 0.06 \%$ Mn, $0.02 \%$ Mo, and $1.3 \%$ EDTA; Plant Products Company Ltd.) at $2.73 \mathrm{~g} \mathrm{liter}^{-1}$.

Pathogen culture. The three isolates of $S$. musiva used in this experiment were
Table 1. Hybrid parentage and clone number for comparing wound and spray inoculations

\begin{tabular}{lc}
\hline Hybrid parentage & No. of clones \\
\hline Populus balsamifera $\times$ P. maximowiczii & 8 \\
$P$. deltoides $\times$ P. maximowiczii & 3 \\
$P$. maximowiczii $\times$ P. balsamifera & 5 \\
\hline
\end{tabular}


obtained from typical Septoria cankers from dormant Populus balsamifera L. trees at the Al-Pac mill site in northern Alberta. Surface disinfested bark was removed from the canker, and a sliver of necrotic tissue was removed and placed on a petri dish with K-V8 (13) (180 ml of V8 juice [Campbell Soup Company, Camden, NJ], $2 \mathrm{~g}$ of calcium carbonate, $20 \mathrm{~g}$ of agar [Difco Laboratories, Franklin Lakes, NJ], and $820 \mathrm{ml}$ of deionized water) growing medium amended with chloramphenicol at $300 \mathrm{mg} \mathrm{liter}^{-1}$ and streptomycin sulfate at $25 \mathrm{mg} \mathrm{liter}^{-1}$. These dishes were then sealed with Parafilm and placed on a light bench under Gro-Lux wide-spectrum fluorescent bulbs (Sylvania; Osram $\mathrm{GmbH}$, Munich) at room temperature, where they received $24 \mathrm{~h}$ of light. Pure colonies were obtained by making transfers to $\mathrm{K}-\mathrm{V} 8$ medium and allowed to grow until sporulation occurred. Isolates were stored at $-90^{\circ} \mathrm{C}$ in vials containing $300 \mu \mathrm{l}$ of $50 \%$ glycerol and $700 \mu \mathrm{l}$ of potato dextrose broth (PDB; Difco Laboratories). The species identity, genetic variability, and relative aggressiveness of these three isolates (APB 2, APB 3, and APB 4) was previously reported by LeBoldus et al. (7).

Inoculum applied to wounded trees was a 5-mm-diameter plug of sporulating mycelium cut from a 14-day-old colony of the pathogen growing on K-V8 medium on the light bench described above. Inoculum sprayed on the trees was a suspension of 1 $\times 10^{6}$ conidia liter $^{-1}$ dislodged in sterile distilled water from 14-day-old colonies on K-V8 medium on the light bench described above.

Experimental design and inoculation method. The 16 hybrid poplar clones were nested within three parentages (Table 1). The experimental design was a randomized incomplete block design with three blocks each consisting of 84 randomly arranged trees. Each tree was randomly assigned an inoculation method (henceforth referred to as "wound inoculated" and "spray inoculated") and one of the three isolates (APB 2 , APB 3, or APB 4) so that each combination of isolate, clone, and inoculation method occurred at least twice in all three blocks. Additionally, two control trees per clone per block were included. Each tree was used to conduct a separate mock inoculation, one for the wound inoculation and one for the spray inoculation.

Trees were inoculated 28 days after transplanting on three consecutive days, each day corresponding to a block. Wound inoculations were conducted by first removing the third fully expanded leaf from the shoot apex (10). A sporulating plug of mycelium measuring $5 \mathrm{~mm}$ in diameter was then placed over the wound and wrapped in Parafilm (10). The excess agar was removed from this plug so that only mycelium was placed on the wound. Mock-inoculated control trees were treated in the same manner except that sterile $\mathrm{K}$ was removed from all stems 14 days after inoculation. Six weeks following inoculation, disease severity was rated on a 1-to-5 scale $(1=$ wound healed with no callus tained by callus, $4=$ necrosis extending beyond callus, and $5=$ encirclement of the stem) (6).

Prior to spray inoculation, tree height was measured. The trees were then removed from the greenhouse and the entire stem was sprayed, excluding leaves and petioles, with a conidial suspension of one of the three isolates (APB 2, APB 3, APB 4 , or sterile distilled water for mockinoculated controls) until runoff. A total of 1.5 liters of spore suspension was used for each block, $500 \mathrm{ml} /$ isolate. Each tree was placed in a separate black plastic garbage bag with two pieces of moist paper towel. The plastic bags were then sealed for $48 \mathrm{~h}$ and kept in a dark room at $26.5^{\circ} \mathrm{C}$, after which time the trees were returned to their original positions in the greenhouse. Twenty-one days after inoculation, the number of necrotic stem lesions per tree was counted. Tree height at the time of inoculation was used to determine the
V8 medium was used. Finally, the Parafilm formation, 2 = callus, 3 = necrosis con-

number of stem lesions per centimeter of tree height which was used to express disease severity.

Pathogen reidentification. Ten trees with necrotic lesions were randomly selected from the experiment described above. Cultures were conducted from four lesions per tree by first disinfesting and then removing the bark from the lesion; subsequently, four slivers of necrotic tissue were removed from the underlying xylem, at the margin of the lesion, and placed on $\mathrm{K}-\mathrm{V} 8$ growth media. Fourteen days later, the petri dishes were examined for the presence of S. musiva, which was identified on the basis of conidial morphology.

Statistical analyses. The SAS MIXED procedure (8) was used to conduct all statistical analyses. Beginning with the initial model, the likelihood ratio $\chi^{2}$ test was used to determine the significance of random factors which were evaluated in the following sequence: (i) the two-way interaction of clone-isolate and (ii) the main effects of clone, isolate, hybrid parentage, and block. For both (i) and (ii), the order of testing was determined by the magnitude default $Z$ test, with the factors with the largest $P$ value being tested first. The nonsignificant

Table 2. Hybrid parentage and number of clones for the hybrid poplar screening trial

\begin{tabular}{lc}
\hline Hybrid parentage & No. of clones \\
\hline Populus balsamifera $\times$ P. maximowiczii & 3 \\
$(P . \times \text { petrowskyana })^{\mathrm{a}, \mathrm{b}} \times P$. maximowiczii & 17 \\
$(P . \times \text { petrowskyana })^{\mathrm{b}} \times P$. maximowiczii & 5 \\
$(P . \times \text { petrowskyana })^{\mathrm{a}, \mathrm{b}} \times P$. nigra & 2 \\
\hline
\end{tabular}

${ }^{a}$ The $P . \times$ petrowskyana parent for these parentages were the same individual.

${ }^{\text {b }}$ P. laurifolia $\times$ P. nigra.

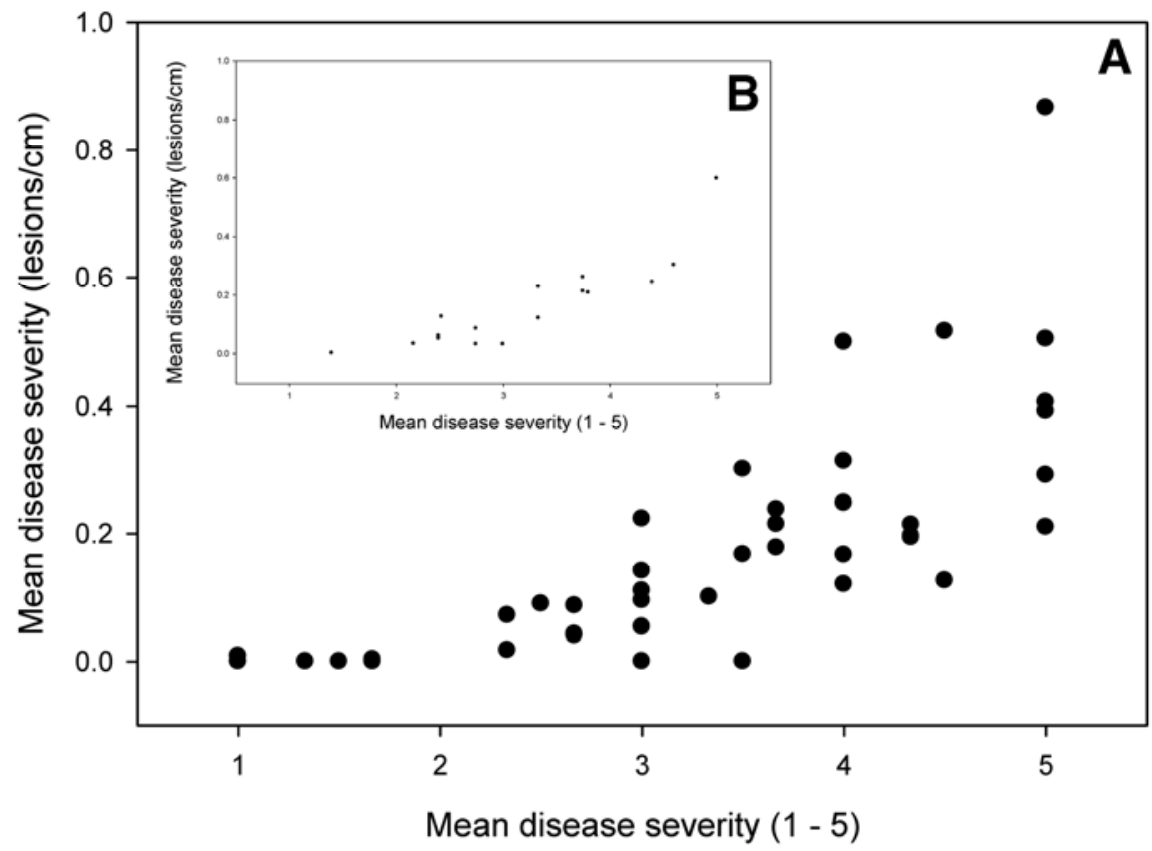

Fig. 1. A, Mean disease severity (lesions $\mathrm{cm}^{-1}$ ) resulting from spray inoculation versus mean disease severity (1 to 5) resulting from wound inoculation for each clone-isolate combination averaged across all three blocks. B, Mean disease severity (lesions $\mathrm{cm}^{-1}$ ) resulting from spray inoculation versus mean disease severity ( 1 to 5 ) resulting from wound inoculation for each clone averaged across all three isolates and blocks. 
random factors were removed from the model at each step. The significance of clone, isolate, hybrid parentage, block, and the clone-isolate interaction were assessed based on their significance in the final model $(\alpha=0.05)$, and the proportion of the explained variability that they accounted for was calculated.

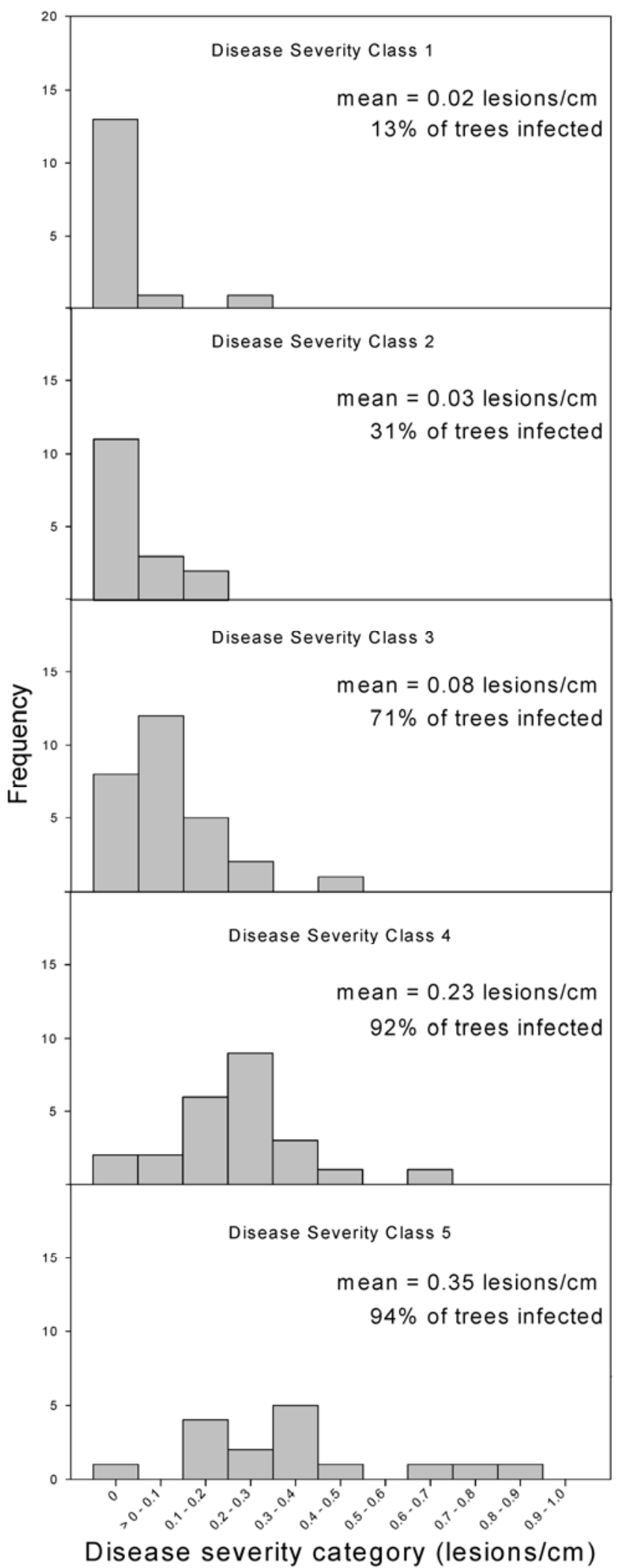

Fig. 2. Five histograms demonstrating the relationship between results of wound and spray inoculation. Frequency distribution is for trees having the same combination of clone, isolate, and block as trees having a particular disease severity following wound inoculation. Disease severity following spray inoculation categories were such that the first category included trees with no lesions and subsequent categories ranged from $>0$ to 1.0 lesions $\mathrm{cm}^{-1}$, increasing by increments of 0.1 lesions cm $\mathrm{cm}^{-1}$.

In addition, histograms were constructed to compare the results of wound and spray inoculations. First, each tree (corresponding to a unique combination of clone, isolate, and block) that had been wound inoculated was classified into one of the five disease-severity classes described above. Then, a series of histograms were constructed, one per disease-severity class, to show the frequency of different diseaseseverity classes among spray-inoculated trees having the same combination of clone, isolate, and block as the woundinoculated trees with that particular disease severity. For each histogram, there were 11 disease-severity classes; all trees with no stem lesions were placed in 1 category and all other trees were placed in 1 of 10 categories (from $>0$ to 1.0 lesions $\mathrm{cm}^{-1}$ by increments of 0.1 lesions $\mathrm{cm}^{-1}$ ). For example, if there were 15 trees with a disease severity of 1 following wound inoculation, a histogram was constructed for the 15 trees with the same combination of clone, isolate, and block that had been spray inoculated to show the frequency distribution of disease severity following spray inoculation, associated with disease-severity class 1.

Finally, the results obtained using the two inoculation methods were compared by plotting disease severity following spray inoculation against disease severity following wound inoculation. This was done separately for each clone (averaged over both isolate and block) and for each clone-isolate combination (averaged over blocks).

Part II. Screening trials.

$P$. balsamifera screening trial. Dormant 1-year-old rooted cuttings of 69 clones of $P$. balsamifera, from 23 provenances, were received from Al-Pac at the beginning of June 2009. Ten trees from each clone were planted in 28 styroblocks (Beaver Plastics Ltd., Acheson, AB, Canada) and grown in the greenhouse, described above, for approximately 42 days prior to inoculation. The trees were fertilized weekly with a $500 \mathrm{ppm}$ solution of 15-30-15 fertilizer (Plant Products Company Ltd.) for the duration of the screening trial.

The experimental design was a randomized complete block design. Each block was comprised of seven styroblocks, with each styroblock containing 20 cavities. At the time of planting, trees were randomly assigned in pairs of the same clone to styroblocks, such that the first six styroblocks contained one pair of trees for each of 10 clones, and the seventh styroblock contained 9 clonal pairs. Fourteen days prior to inoculation, each pair of trees was evaluated and the tree with the best growth was selected. At the time of inoculation, each block contained 69 trees.

Forty-one days after planting, the height of the current season's growth of each tree (distance from previous year's bud scale scar to the shoot apex) was measured. The 
following day, all trees were inoculated. Inoculation and incubation was conducted as described above, except that each plastic garbage bag contained an entire styroblock and the spore suspension mixture used contained equal parts of each of the three isolates. The number of lesions per stem was counted 21 days after inoculation. The current year's growth at the time of inoculation was then used to determine the number of lesions per centimeter for each tree.

Hybrid poplar screening trial. The hybrid poplar screening trial was identical to that described for $P$. balsamifera with the following exceptions: (i) branch cuttings from 27 clones nested within four parentages were inoculated (Table 2), (ii) there were 10 replicate plants of each clone, and (iii) there were, in total, 14 styroblocks arranged in a completely randomized design with a total of 270 trees.

Statistical analyses. Model selection for the two screening trials was conducted as described above. Significance of the random factors for the two experiments was assessed based on their significance in the final model $(\alpha=0.05)$ and the proportion of the explained variability that they accounted for was calculated.

\section{RESULTS AND DISCUSSION}

The majority of studies evaluating the variability in resistance to canker development of Populus spp. inoculated with $S$. musiva have relied on wounds to create infection courts $(2,3,6,14-17)$. In five studies where nonwounded trees were inoculated, the frequencies of cankers were relatively low or unreported. For example, Bier (2) achieved successful lesion production on nonwounded rooted cuttings of hybrid poplar in a greenhouse experiment but did not present his data. Furthermore, in three other greenhouse experiments where young trees were inoculated, Waterman (15), Filer et al. (3), and Long et al. (9) achieved 10.0, 20.0, and 3.0\% successful infection, respectively. Zalasky (17), inoculating seedlings under greenhouse conditions, reported frequencies of cankers ranging from 0 to $31.6 \%$ for seedlings of $P$. balsamifera collected from six source areas; however, only a single group of trees, from one geographic source area, had cankers on greater than $15.0 \%$ of inoculated seedlings. Such low infection frequencies would make it difficult to evaluate stem resistance using spore inoculation of nonwounded trees or to conduct epidemiological studies.

In contrast, the three experiments described in this study demonstrate that it is possible to achieve high lesion frequencies by applying a spore suspension to nonwounded tissue. Disease severity following spray inoculation was correlated with severity in the wound-inoculated trees. The disease-severity rating system for wound inoculations was such that disease severities less than 3.0 were considered likely to be resistant and disease severities greater than 3.0 were considered likely to be susceptible. All clones with a mean disease-severity ranking greater than 3.0 for wound inoculation had a mean disease incidence greater than 0.1 lesions $\mathrm{cm}^{-1}$ for spray inoculation. Conversely, all clones with a mean disease severity less than 3.0 for wound inoculation had a mean disease severity less than 0.1 lesions $\mathrm{cm}^{-1}$ for spray inoculation, with the exception of a single clone within the $P$. deltoides-P. balsamifera hybrid parentage (Fig. 1B). S. musiva was successfully cultured from 35 of the 40 lesions sam-

pled. No effort was made to identify any of the other fungi.

The close association between disease severity following wound inoculation and disease severity following spray inoculation was also apparent in the histograms of disease severity following spray inoculation associated with different classes of severity following wound inoculation (Fig. 2 ). As disease severity increased following wound inoculation, the histogram of mean disease severity following spray inoculation shifted to the right, with fewer individuals in the lower disease-severity categories and more in the higher disease-severity categories (Fig. 2). The average disease severity and percentage of trees with at least one lesion also increased as the category of disease severity following wound inoculation increased (Fig. 2); for disease-severity categories 4 and 5 , over $90 \%$ of stems had at least one lesion (Fig. 2).

However, there were two differences between results obtained using the two inoculation methods. First, there was a significant clone-isolate interaction following spray inoculation $(P<0.001$; Table 3$)$. Second, the variability in disease severity among clones following spray inoculation increased with increasing disease severity following wound inoculation. Low severity

Table 4. Analysis of variance for the Populus balsamifera screening trial with the variance components partitioned among sources ${ }^{\mathrm{a}}$

\begin{tabular}{lrccc}
\hline $\begin{array}{l}\text { Source of } \\
\text { variation }\end{array}$ & df & $\boldsymbol{P}$ value & Variance estimate & $\begin{array}{c}\text { Proportion of } \\
\text { explained variance }\end{array}$ \\
\hline Block & 3 & 0.157 & $<0.001$ & $<0.001$ \\
Provenance & 22 & 0.089 & - & - \\
Clone & 68 & $<0.001$ & 0.006 & 0.32 \\
Residual & 161 & $\mathrm{nt}$ & 0.013 & 0.68 \\
Total & 254 & $\mathrm{nt}$ & - & 1.00 \\
\hline
\end{tabular}

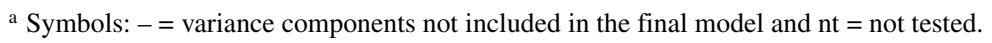

Table 5. Analysis of variance for the hybrid poplar screening trial with the variance components partitioned among sources ${ }^{\mathrm{a}}$

\begin{tabular}{lrccc}
\hline $\begin{array}{l}\text { Source of } \\
\text { variation }\end{array}$ & df & $\boldsymbol{P}$ value & Variance estimate & $\begin{array}{c}\text { Proportion of } \\
\text { explained variance }\end{array}$ \\
\hline Hybrid parentage & 5 & 1.000 & - & - \\
Clone & 28 & $<0.001$ & 0.005 & 0.42 \\
Residual & 223 & $\mathrm{nt}$ & 0.008 & 0.58 \\
Total & 256 & $\mathrm{nt}$ & - & 1.00 \\
\hline
\end{tabular}

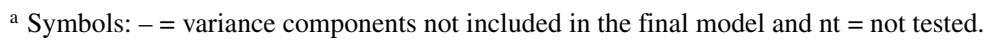

Table 3. Analysis of variance table with variances partitioned among sources for both the wound-inoculation and spray-inoculation protocols ${ }^{\mathrm{a}}$

\begin{tabular}{|c|c|c|c|c|c|c|c|}
\hline \multirow[b]{2}{*}{ Source of variation } & \multirow[b]{2}{*}{ df } & \multicolumn{3}{|c|}{ Wound-inoculation model } & \multicolumn{3}{|c|}{ Spray-inoculation model } \\
\hline & & $P$ value & Variance estimate & Proportion $^{b}$ & $P$ value & Variance estimate & Proportion $^{\mathrm{b}}$ \\
\hline Block & 3 & 1.000 & 0.005 & $<0.001$ & 1.000 & 0 & 0 \\
\hline Hybrid parentage & 2 & 0.114 & - & - & 1.000 & - & 0 \\
\hline Clone & 15 & $<0.001$ & 1.295 & 0.65 & 0.005 & 0.008 & 0.26 \\
\hline Isolate & 2 & 1.000 & - & - & 0.237 & - & - \\
\hline Clone-isolate & 30 & 1.000 & - & - & $<0.001$ & 0.006 & 0.19 \\
\hline Residual & 87 & $\mathrm{nt}$ & $0.695^{\mathrm{c}}$ & 0.34 & $\mathrm{nt}$ & $0.017^{\mathrm{c}}$ & 0.55 \\
\hline Total & 139 & $\mathrm{nt}$ & - & 1.00 & $\mathrm{nt}$ & - & 1.00 \\
\hline
\end{tabular}

a Symbols: $-=$ variance components not included in the final model and $\mathrm{nt}=$ not tested.

${ }^{\mathrm{b}}$ Proportion of explained variance.

${ }^{c}$ Variances of the residuals were not equal; therefore, they were modeled independently. The residual value reported was calculated by averaging the variances of the three independent isolate residuals. 
resulting from spray inoculation among clone-isolate combinations with high disease severity following wounding may have occurred due to resistance mechanisms that were bypassed by the wounding process. Alternatively, low disease severity resulting from spray inoculation may have resulted from disease escape. Due to the epidemiological importance of an interaction effect, the difficulty of detecting physiological specialization (5), and the potential of wound inoculations for circumventing resistance mechanisms, further investigations of these phenomena are warranted.

Regardless of whether the goal is to evaluate resistance or epidemiological processes, an artificial inoculation method should have sufficiently small experimental error to permit detection of treatment effects with a practical number of experimental units. In the case of all three nonwounded spray-inoculation experiments (Tables 3, 4, and 5), the variability due to experimental error was similar to that of both the wound inoculations (Table 3 ) and previously reported values $(6,14)$. Furthermore, the lack of a block effect in the $P$. balsamifera inoculation experiment $(P=$ 0.192 ; Table 4) and wound versus spray inoculation experiment $(P=1.000$; Table $3)$ indicates a reasonably high level of reproducibility with spray inoculations.

In the three experiments described above, lesions per centimeter 3 weeks after inoculation was used as the index of disease severity. This relatively short period of time between inoculation and severity rating was determined based on observations from a preliminary trial in which lesions were allowed to develop for 6 weeks. In this preliminary trial, lesions were typical of Septoria cankers but often coalesced after approximately 4 weeks, making it impossible to evaluate lesion number.

The success of the spray inoculation protocol allows the examination of many different aspects of the Populus spp. $-S$. musiva interaction that were previously impossible to address. Researchers will now be able to determine the infection court(s) and describe the responses of clones to conidial inoculation in detail. Furthermore, it will be possible to determine the effect of various environmental parameters on infection, evaluate epidemiological parameters such as the relationship between inoculum concentration and disease severity, and screen protectant fungicides for their efficacy in preventing infection. Finally, this spray inoculation protocol may prove to be the best way to screen trees in tree-improvement programs for resistance to infection. There are a number of reasons why it might be more desirable to conduct spray inoculations in resistance trials: (i) speed (disease severity in terms of number of lesions per unit of stem length can be rated after 3 weeks rather than 6 weeks for disease severity), (ii) the ability to inoculate a single tree with multiple isolates, and (iii) the potential that results reflect resistance to penetration or other mechanisms expressed prior to visible lesion development. The results of these three experiments clearly show that it is possible to obtain reliably high frequencies of canker (or lesion) development that may be adequate to detect differences among clones, isolates, and, potentially, clone-isolate interactions.

\section{ACKNOWLEDGMENTS}

We thank Alberta-Pacific Forest Industries Inc. (Al-Pac), who supplied the cuttings for these experiments; D. Kamelchuk, S. Hayward, and S. Cosgrove for collection of the plant material; $\mathrm{K}$. Jansen for help in conducting the greenhouse trials and collecting the data; The Natural Sciences and Engineering Research Council of Canada (NSERC) and Al-Pac for their financial support; the Canadian Forest Service for a CFS-NSERC-Industry Forest Research Partnership grant to P. V. Blenis; Al-Pac for supporting an IPS scholarship to J. M. LeBoldus; West Fraser Timber Co. Ltd. for the West Fraser Scholarship in Enhanced Forest Management; and the two anonymous reviewers who helped greatly to improve this manuscript.

\section{LITERATURE CITED}

1. Ares, A., and Butierrez, L. 1996. Selection of poplar clones for the lower valley of the Colorado River, Argentina. Forestry 69:75-82.

2. Bier, J. E. 1939. Septoria canker of introduced and native hybrid poplars. Can. J. Res. 17:195204.
3. Filer, T. H., McCraken, F. I., Mohn, C. A., and Randall, W. K. 1971. Septoria canker on nursery stock of Populus deltoides. Plant Dis. Rep. 55:460-463.

4. Krupinsky, J. M. 1989. Variability in Septoria musiva in aggressiveness. Phytopathology 79:413-416.

5. Kulkarni, R. N., and Chopra, V. L. 1982. Environment as the cause of differential interaction between host cultivars and pathogenic races. Phytopathology 72:1384-1386.

6. LeBoldus, J. M., Blenis, P. V., and Thomas, B. R. 2008. Clone by isolate interaction in the hybrid poplar-Septoria musiva pathosystem. Can. J. For. Res. 38:1888-1896.

7. LeBoldus, J. M., Blenis, P. V., Thomas, B. R., Feau, N., and Bernier, L. 2009. Susceptibility of Populus balsamifera to Septoria musiva: a field study and greenhouse experiment. Plant Dis. 93:1146-1150.

8. Littell, R. C., Milliken, G. A., Stroup, W. W., Wolfinger, R. D., and Schabenberger, O. 2006 SAS for Mixed Models, second ed. SAS Institute Inc., Cary, NC.

9. Long, R., Bowersox, T. W., and Merrill, W. 1985. Artificial inoculation of Populus hybrids with Septoria musiva. Can. J. For. Res. 16:405-407.

10. Mottet, M.-J., Bussières, G., and Vallée, G. 1991. Test précoce pour l'évaluation de la sensibilité de peupliers hybrides au chancre septorien. For. Chron. 67:411-416.

11. Newcombe, G., Ostry, M. E., Hubbes, M., Périnet, P., and Mottet, M.-J. 2001. Poplar diseases. Pages 249-276 in: Poplar Culture in North America. D. I. Dickmann, J. G. Isebrands, J. E. Eckenwalder, and J. Richardson, eds. NRC Research Press, National Research Council of Canada, Ottawa, ON, Canada.

12. Ostry, M. E., and McNabb, H. S., Jr. 1985. Susceptibility of Populus species and hybrids to disease in the north central United States. Plant Dis. 69:755-757.

13. Stanosz, J. C., and Stanosz, G. R. 2002. A medium to enhance identification of Septoria musiva from poplar cankers. For. Pathol. 32:145-152.

14. Ward, K. T., and Ostry, M. E. 2005. Variation in Septoria musiva and the implications for disease resistance screening of poplars. Plant Dis. 89:1077-1082.

15. Waterman, A. M. 1954. Septoria canker of poplars in the United States. U.S. Dep. Agric. Circ. 947.

16. Weiland, J. E., Stanosz, J. C., and Stanosz, G. R. 2003. Prediction of long-term canker disease damage from the responses of juvenile poplar clones to inoculation with Septoria musiva. Plant Dis. 87:1507-1514.

17. Zalasky, H. 1978. Stem and leaf spot infection caused by Septoria musiva and S. populicola on poplar seedlings. Phytoprotection 59:43-50. 